\begin{tabular}{|c|l|}
\hline Title & $\begin{array}{l}\text { The relationships between feeding-group size and feeding rate vary from positive to negative with characteristics of } \\
\text { food items in wild Japanese macaques (Macaca fuscata) }\end{array}$ \\
\hline Author(s) & Kazahari, N.; Tsuji, Y.; A getsuma, N. \\
\hline Citation & $\begin{array}{l}\text { Behaviour, 150(2), 175-197 } \\
\text { https://doi.org/10.1163/1568539X-00003044 }\end{array}$ \\
\hline Issue Date & 2013 \\
\hline Doc URL & http://hdl.handle.net/2115/52970 \\
\hline Type & article(author version) \\
\hline File Information & Kazahari et al_2013_.pdf \\
\hline
\end{tabular}

Instructions for use 


\title{
The relationships between feeding-group size and feeding rate vary from positive to negative with characteristics of food items in wild Japanese macaques (Macaca fuscata)
}

\author{
N. Kazahari a , Y. Tsuji ${ }^{b}$ and N. Agetsuma ${ }^{c}$ \\ a Wildlife Research Center of Kyoto University, Tanaka-Sekiden-cho 2-24, Kyoto, Japan \\ ${ }^{\text {b }}$ Primate Research Institute, Kyoto University, Kanrin, Inuyama, Aichi, Japan \\ c Wakayama Experimental Forest, Field Science Center for Northern Biosphere, Hokkaido University, Hirai 559, Kozagawa, \\ Wakayama, Japan
}

(Accepted 15 December 2012)

\begin{abstract}
To understand the costs and benefits of group-living, it is important to clarify the impacts of other individuals on foraging success. Previous studies on group-living primates have focused on the relationship between feeding-group size and feeding rate in food patches, and have exhibited inconsistent results, showing positive, neutral, or negative relationships. The relationship realized will depend on the balance of positive and negative impacts of co-feeding on feeding rate. The intensity of negative impacts (i.e., feeding competition) may vary with some characteristics of food items such as (1) patch size, (2) within-patch food density, (3) within-patch distribution pattern of food, (4) the abundance and (5) distribution pattern of within-habitat food trees, and (6) the relative energy content among available food items. Thus, the balance of positive and negative impacts of co-feeding, and ultimately the relationship between feeding-group size and feeding rate, is expected to change with characteristics of food items. In this study of wild Japanese macaques (Macaca fuscata), the relationship between feeding-group size and feeding rate, and the above six characteristics of 12 main food items were assessed over six seasons. Positive, neutral, or negative relationships between feeding-group size and feeding rate were detected among these food items. Positive relationships were consistently associated with within-patch food density; higher food density within food patches was likely to lead to positive relationships. Thus, various relationships between feeding-group size and feeding rate should be attributed to these specific characteristics of food items, which alter the degree of feeding competition.
\end{abstract}

Keywords Feeding competition, foraging success, group-living, patch use, food condition.

\section{Introduction}

Foraging behaviour has often been assumed to embody optimal foraging strategies, which maximize energy intake rate (e.g., Stephens \& Krebs, 1986). Patch models have been proposed to explain optimal foraging strategies in patchy food environments (e.g., Charnov, 1976; Iwasa et al., 1981). The models assume that feeding rates (i.e., number of food items consumed per feeding time) are positively correlated with patch quality. Foraging on a food patch causes declines in feeding rate because of food depletion in the patch. To optimize feeding rate, patch models predict that foragers should give up the patch within an adequate time and explore other food patches to maintain higher feeding rates. Patch models have 
received support from numerous studies of various species in solitary-foraging situations (e.g., in birds: Krebs et al., 1974; Cowie, 1977; Kacelnik, 1984; in insects: Schmid-Hempel et al., 1985; in primates: Agetsuma, 1998). However, foraging behaviours of group-living animals often deviate from the predictions of patch models. For example, foragers cannot always leave food patches within the timeframe of optimal foraging. Primates often leave food patches because of interference from dominants or to follow other group members (Nakagawa, 1990). Birds sometimes adjust their patch-leaving behaviour to coincide with other members' departure decisions (Livoreil \& Giraldeau, 1997).

In general, group-living is maintained by cost-benefit tradeoffs among foraging success, predation avoidance, and disease transmission (Alexander, 1974; Terborgh, 1983; Clark \& Mangel, 1986). In primates, costs and benefits in foraging and predation avoidance have been connected with groupliving (Wrangham, 1980; van Schaik, 1983). Sharing foods among group members decreases feeding rate through food consumption (i.e., withingroup scramble feeding competition) and through food monopolization by dominants (i.e., within-group contest feeding competition) (Janson, 1988; Janson \& van Schaik, 1988; Thouless, 1990; Krause \& Ruxton, 2002). Conversely, the presence of other members improves feeding rate through the reduction of necessary vigilance against predators (Berger, 1978; Caraco, 1979; Sullivan, 1984) and the effective defense of favorable food resources from other groups under inter-group competition (Wrangham, 1980). Feeding rate can also be improved by the presence of co-feeders through a reduction in the visual scanning necessary to maintain contact with group members (Kazahari \& Agetsuma, 2010).

To evaluate feeding competition in group-living, relationships between feeding-group size (number of foragers sharing food patches) and feeding rate have been studied in primates. To date, contradictory relationships have been reported. In several studies, feeding-group size was not found to affect feeding rate (e.g., howler monkeys, Alouatta palliata: Chapman, 1988; olive baboons, Papio anubis: Barton, 1993). However, feeding-group size negatively affected feeding rate through patch depletion in red colobus monkeys (Piliocolobus tephrosceles) (Snaith \& Chapman, 2005). Feeding group size also decreased feeding rate in chimpanzees (Pan troglodytes schweinfurthii) (Furuichi \& Hashimoto, 2007). Moreover, in Japanese macaques (Macaca fuscata), under food-rich conditions, feeding-group size increased the feeding rate (Kazahari \& Agetsuma, 2008). It is important to clarify conditions under which the presence of others acts as a cost or benefit for foraging individuals in order to understand how group-living has evolved. However, to date, few studies have revealed the mechanisms determining the relationships between feeding-group size and feeding rate. The contradictory relationships in previous studies may be attributed to differences in the balance between the positive and negative impacts of feeding-group size on feeding rate (Kazahari \& Agetsuma, 2010).

The present paper focused on factors that change the relationship between feeding-group size and feeding rate. In smaller patches, within-group feeding competition (i.e., negative impact of feeding-group size) increases (Mitchell et al., 1991). Lower density and clumped distribution of food could also 
strengthen feeding competition (within-patch distribution of foods: Peres, 1996; within-habitat distribution of patches: Barton, 1993; McFarland, 1988). Additionally, attractive food items containing more energy induce intensive feeding competition (Saito, 1996; Tsuji \& Takatsuki, 2012). We, therefore, hypothesized that these characteristics of food items, i.e., food patch size, within-patch food distribution (food density and cohesiveness), within-habitat patch distribution (patch density and cohesiveness), and relative energy content among potential food items, modify the intensity of feeding competition and change the balance between the positive and negative impacts of group members on feeding rate. Therefore, such food characteristics should determine the relationships between feeding-group size and feeding rate. Based on this hypothesis, different patterns of relationships (i.e., positive, neutral, or negative relationships) are realized among food items. Food items with characteristics that provoke feeding competition would induce negative relationships, and vice versa. In the present study, we (1) confirmed various patterns of these relationships (i.e., positive, neutral, and negative relationships) between feeding-group size and feeding rate among different food items in wild Japanese macaques and (2) examined how characteristics of food items were associated with patterns in these relationships.

Japanese macaques shift their diets in response to overall food availability, which varies seasonally and annually (Agetsuma, 1995b; Hill \& Agetsuma, 1995; Tsuji et al., 2006). Patch size, within-patch food distribution, within-habitat patch distribution, and nutritional content differ among food items consumed by Japanese macaques (patch size: Agetsuma, 1995a; within-patch food distribution: Tsuji, 2011; within-habitat patch distribution: Agetsuma, 1995a; Saito, 1996; nutritional content: Nakagawa, 1989; Saito, 1996). Furthermore, even for the same food item, the relative value for foragers may differ with seasons and years, reflecting the availability of other food items. Thus, this species is a good subject to use in the examination of our hypothesis.

\section{Methods}

\subsection{Study site and subjects}

The study was conducted on Kinkazan Island (ca. $10 \mathrm{~km} 2)$, northern Japan (38 $16 \_\mathrm{N}, 141^{\circ} 35$ E). The island was covered with mixed forest of coniferous and broad-leaved trees (Yoshii \& Yoshioka, 1949). There were six groups of wild Japanese macaques on the island, with a total population of 221 (Izawa, 2005). All groups were free ranging and have never been provisioned. One habituated group (B1 group) was studied for six seasons according to the combination of available food items: mid-spring (April 2005); late spring (May-beginning June 2005); early summer (middle June 2005); early autumn (September 2006); mid-autumn (mid-October 2006); and late autumn (end of October-November 2006). The group consisted of 13 adult females ( 7 years old), two adult males ( 7 years old), $0-1$ young females (5-6 years old), six juveniles (1-4 years old), and 0-8 infants ( $<1$ year old) during the observation periods. The lineal dominance hierarchy among all adult females was determined following the dominance directed tree 
method (Izar et al., 2006) in a previous study (Kazahari \& Agetsuma, 2008). In each season, we chose 4-6 of the 8 parous females as study subjects to collect data on animals of various dominance ranks (Table 1). All focal females had no infants in 2005 and all had infants in 2006. As females finished lactating around half a year after delivery (i.e., around September in the study site) (Tanaka, 1992), the effects of lactation on foraging behaviour in 2006 would not be important in this study.

The macaques on the island are free from predation (Izawa, 1983). In addition, agonistic interactions between neighbouring groups rarely occur at the study site (Saito et al., 1998). In fact, a group encounter was observed only once during the study periods, and this did not entail any agonistic interactions. Therefore, the macaques were not exposed to severe inter-group direct feeding competition. Thus, predation avoidance and inter-group feeding competition were not assumed to affect feeding rate. In general, males show high aggression toward females during the mating season (Barrett et al., 2002), and the feeding behaviour of females may be affected by aggressive non-group males. However, this effect would be negligible in our study, as the subject group had no oestrus females, and few non-group males aggregated around the group during the mating season in 2006 (September, mid-October, and end of October-November).

\subsection{Food-patch definition}

On the island, food patches could be classified into three categories: arboreal patches (leaves, flowers, seeds, and fruits), ground patches (fallen seeds and fruits), and herb and shrub patches. Trees were sparse due to heavy grazing by sympatric sika deer (Cervus nippon) (Maruhashi et al., 1998; Takatsuki, 2009), and each food tree could easily be defined as a discrete food patch (Nakagawa, 1990). For arboreal and ground patches, a tree crown and the ground beneath the crown cover of a tree, respectively, were assumed to be a food patch. When several crowns connected with one another, neighbouring crowns or crown covers were treated as the same food patch. For herbal and shrub patches, each community was assumed to be one food patch. On the island, ground cover below trees was rare (Ito, 1974), and herbaceous/shrubby plants, which are not preferred by sika deer, have developed simple communities in large gaps (Yoshioka, 1972). Thus, it was easy to distinguish ground patches from herbal/shrub patches.

\subsection{Foraging behaviour and feeding-group size}

Behavioural data were collected using the focal animal sampling method (Altmann, 1974). During each observation day, one of the 4-6 target females was followed from dawn to dusk with as few interruptions as possible (Table 1). The total observation time was $416 \mathrm{~h}$.

While following the focal females, behavioural data were collected continuously during 8-min observation sessions (Kazahari \& Agetsuma, 2008). The focal animal's behaviour was recorded by 
seconds during the first 4 min of each session. Behaviour was classified as foraging, travelling, or inactive including resting and self- and social grooming. When the females were foraging in food patches, the eaten food items (plant species and parts) were recorded. The number of food units (unit: the number of items that amacaque puts into its mouth at one time) consumed and the time spent consuming those units (hereinafter referred to as 'feeding time'), including handling and chewing, were also recorded by seconds to evaluate feeding rate (i.e., the number of food units consumed per feeding time). Aggressive events between focal and other females (e.g., attack and replacement after approaches within $1 \mathrm{~m}$ ) were also recorded. Soon after the first 4 min of each session, the number of other individuals in the same food patch as the focal female was counted as a measure of feeding-group size. The geographical locations of focal females were also recorded every 8 min by GPS (EMPEX, Pokenavi map21EX).

Table 1. The number of target females and the average following time in each season.

\begin{tabular}{lcc}
\hline Season & Dominane rank of focal females & $\begin{array}{c}\text { Following time per focal female } \\
\text { (mean } \pm \text { SD h) }\end{array}$ \\
\hline \hline Mid-spring (April 2005) & $1,6,9,13$ & $17.7 \pm 2.1$ \\
Late spring (May-beginning June 2005) & $1,5,6,9,13$ & $17.2 \pm 5.5$ \\
Early summer (middle June 2005) & $1,5,6,9,13$ & $14.1 \pm 4.3$ \\
Autumn (September 2006) & $1,2,5,11,12$ & $19.1 \pm 2.1$ \\
Mid-autumn (middle October 2006) & $1,2,12,13$ & $11.8 \pm 1.6$ \\
Late autumn (end of Octover-Nobenber 2006) & $2,5,9,12,13$ & $9.4 \pm 2.1$ \\
\hline
\end{tabular}

\subsection{Characteristics of food items}

The percentage of a given food item in the diet was calculated by dividing the number of sessions in which focal females were feeding on the given food item by the total number of sessions in which they were feeding in each season. A total of 21 food items were defined as main food items, which consisted of _ $5 \%$ of the diet in each season (Table 2). Among these, 12 main food items (I-XII) were analyzed in this study; other main food items were excluded from the analysis because of insufficient sample size. Six characteristics related to feeding competition were surveyed for these food items: (1) patch size; (2) cluster size of food units; (3) within-patch density of food units; (4) abundance and (5) cohesiveness of within-habitat food trees; and (6) relative energy content among available food items. For the two herbal food items, XI and XII, characteristics (4) and (5) were not surveyed.

\subsubsection{Patch size}

The size of food patches used by focal females was estimated. For arboreal patches, the maximum and minimum crown widths and crown depths of trees were measured. Patch sizes were estimated as the 
Table 2. Main and analyzed food items for each season.

\begin{tabular}{|c|c|c|c|c|c|}
\hline ID & Season & Food items ${ }^{* 2}$ & Patch categories ${ }^{\star 3}$ & Percentage of diet (\%) $)^{\star 4}$ & Energy content (kcal/unit) ${ }^{* 5}$ \\
\hline \multirow[t]{4}{*}{ I } & \multirow{3}{*}{ Mid-spring } & Fagus crenata (fl) & $A$ & 57.0 & 0.41 \\
\hline & & Berberis thunbergii (If) & $\mathrm{S}$ & 21.5 & 0.24 \\
\hline & & herbaceous spp. ${ }^{{ }_{1}}$ (ap) & $\mathrm{H}$ & 13.0 & 0.02 \\
\hline & \multirow{4}{*}{ Late spring } & herbaceous spp ${ }^{{ }_{1} 1}$ (ap) & $\mathrm{H}$ & 21.7 & 0.02 \\
\hline \multirow{3}{*}{$\begin{array}{l}\text { II } \\
\text { III }\end{array}$} & & Zelkova serrata (If) & A & 13.0 & 0.29 \\
\hline & & Pourthiaea villosa (fl) & A & 19.8 & 0.21 \\
\hline & & Berberis thunbergii (If) & S & 8.8 & 0.24 \\
\hline \multirow{4}{*}{ IV } & \multirow{4}{*}{ Early summer } & herbaceous spp. ${ }^{{ }_{1}}$ (ap) & $\mathrm{H}$ & 28.6 & 0.02 \\
\hline & & Zelkova serrata (If) & A & 28.8 & 0.29 \\
\hline & & Pourthiaea villosa (fl) & A & 5.3 & 0.06 \\
\hline & & Berberis thunbergii (If) & $S$ & 8.8 & 0.24 \\
\hline V & \multirow{4}{*}{ Autumn } & Cornus brachypode (fr) & $\begin{array}{l}A \\
G\end{array}$ & 22.5 & 0.17 \\
\hline VII & & Castanea crenata (se) & $\begin{array}{l}A \\
G\end{array}$ & 22.3 & 7.63 \\
\hline IX & & Magnolia obovata (se) & $\begin{array}{l}\mathrm{A} \\
\mathbf{G}\end{array}$ & 9.5 & 0.64 \\
\hline$x$ & & Benthamidia japonica (If) & A & 7.7 & 0.36 \\
\hline $\mathrm{XI}$ & Mid-autumn & Perilla frutescens (se) & H & 74.8 & 0.40 \\
\hline \multirow[b]{2}{*}{ XII } & \multirow{2}{*}{ Late autumn } & Oplismenus undulatifolius (ro) & $\mathrm{H}$ & 38.3 & 0.01 \\
\hline & & Perilla frutescens (se) & $\mathrm{H}$ & 28.4 & 0.08 \\
\hline
\end{tabular}

The food items in bold font were analyzed and identified by the IDs.

${ }^{{ }^{*} 1}$ Including several species.

${ }^{\star 2}$ ap, aerial parts; fl, flowers; fr, fruits; If, leaves; ro, roots; se, seeds.

${ }^{* 3} \mathrm{G}$, ground patch; $\mathrm{H}$, herbal patch; $\mathrm{S}$, shrub patch; $\mathrm{A}$, arboreal patch.

${ }^{*}$ Percentage of time spent feeding on each food item were calculated for each season by dividing the total number of sessions with feeding each food item by the total number of sessions with foraging.

${ }^{* 5}$ Energy content included in a food unit. Food unit means the amont of food items that a macaque put into its mouth at one time.

a)

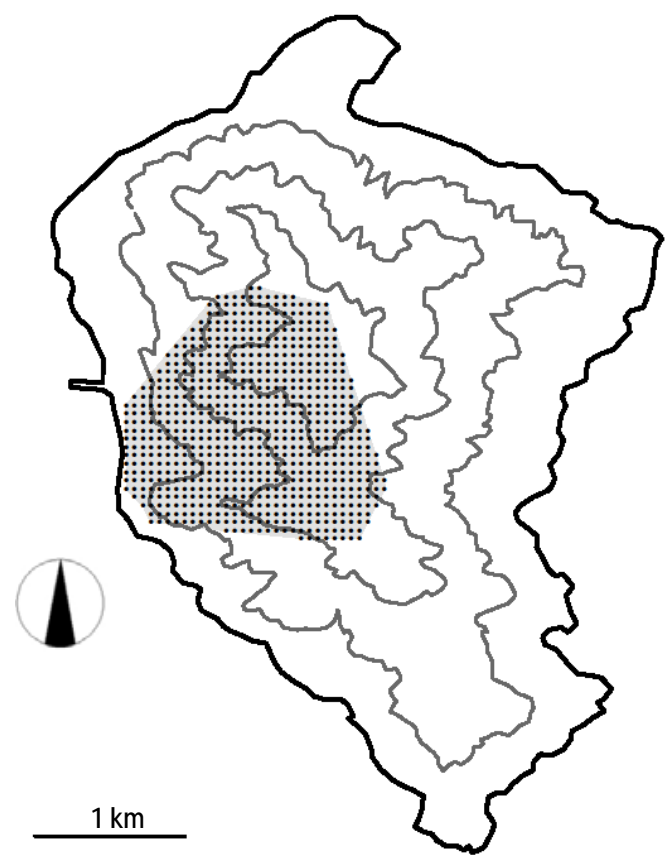

b)

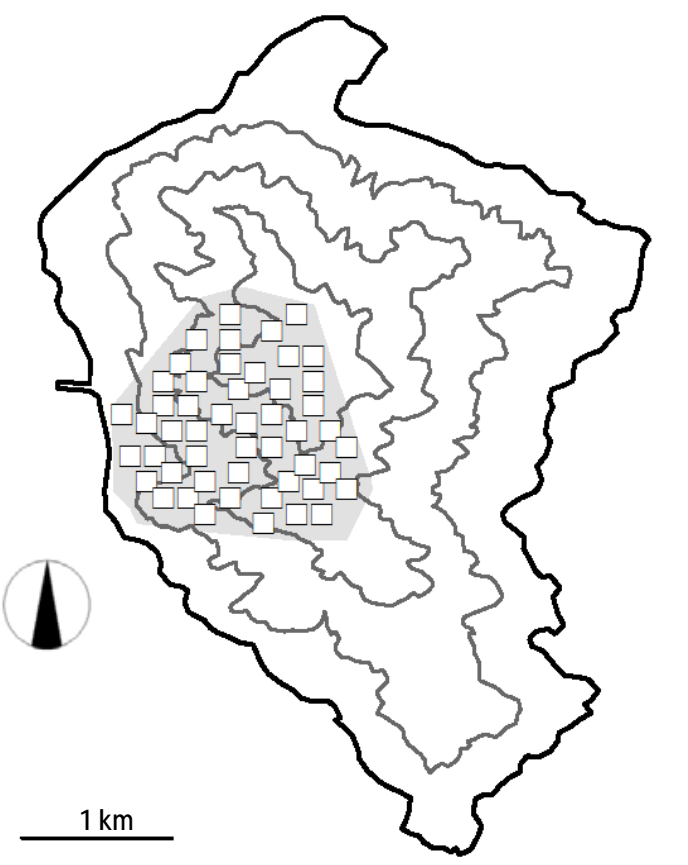

Figure 1. Home range and the location of surveys for herbal patch size and distribution of food trees.

a) Survey point for herbal patch (, survey point).

b) Location of quadrat for survey of food trees ( $\square, 1$-ha quadrat; $\square$, approximate home range). 
crown depths as the height (Kazahari \& Agetsuma, 2008). For ground patches, patch sizes were calculated as the areas of the ellipses using the maximum and minimum crown widths as major and minor axes. For herbal patches, a vegetation survey was conducted in March 2007, and patch sizes were estimated as follows. The approximate range area of the focal females across study periods (ca. 86\%) was compartmentalized into a 50-m grid (Figure 1a). This area fully covered the area in which focal females used herbal patches. Then, the existence or nonexistence of subject plants within approximately $25 \mathrm{~m}$ of grid intersections was recorded. Intersections with a subject plant were assumed to indicate a 250-m2 (i.e., $50 \times 50 \mathrm{~m}$ ) patch size. If connected intersections (east-west and north-south intersections) contained subject plants, all connected intersections were treated as the same patch, and the patch size was the sum of those patch sizes. As the minimum herbal patch area analyzed in this study was estimated to be more than $5000 \mathrm{~m}$, this method provides sufficient resolution to represent actual herbal patch sizes. The size of each food patch was used for the within-food items analysis (i.e., examination (1)). The mean patch size of each food item was also calculated for the inter-food items analysis (i.e., examination (2)).

\subsubsection{Cluster size of food units}

Some food items consist of several food units gathered into a cluster. For example, the seeds of Castanea crenata occur in burrs (i.e., clusters). In this study, three food items (VII and VIII, arboreal and ground patches of Castanea crenata seeds in early autumn, and IX, ground patches of Magnolia obovata seeds in early autumn) form such clusters of food units. For these food items, the number of food units in a cluster was counted ( $N=5$ for each food item), and the mean number of food units in a cluster was defined as the cluster size. For other food items, the cluster size was one. Cluster size was assumed as an indicator of food unit cohesiveness within food patches.

\subsubsection{Within-patch food unit density}

Feeding rate should be affected by within-patch food density (e.g., Whitten, 1988). Thus, the food unit density within each food patch was estimated during the patch residency of focal females. For each food item, we evaluated the densities of food units within patches using a four-level index for all patches at every visit of focal females for the within-food items analysis (i.e., examination (1)). An index of within-patch food unit density of each food patch was assigned using values of 1,2, 3, or 4 from the lowest to the highest density of each food item. This index represented the relative food unit density within a patch of the same food item, but it could not represent food unit density among different food items.

For comparison among different food items, we also recorded actual within-patch food unit density. Whenever possible, we counted the number of food units within $1 \mathrm{~m}_{3}$ in arboreal patches and within $1 \mathrm{~m} 2$ in ground/shrub/herbal patches. For food items VII, VIII and IX, which formed clusters of food units, we could not count the number of food units and instead counted the number of clusters. Then, we estimated 
food unit density by multiplying the number of clusters by the mean cluster size of the food item. The number of food units or clusters was counted only once, as early as possible after the focal female entered a patch. The measurement location within the patch was chosen based on a visual observation to be representative of the entire patch. The within-patch food unit density of each food patch was averaged for each food item for the inter-food items analysis (i.e., examination (2)).

\subsubsection{Abundance and cohesiveness of within-habitat food trees}

The abundance and degree of aggregation of food trees in the habitat were estimated for 10 food items $(I-X)$, excluding herbal patch food items (XI and XII). The dispersion of study group members covered a radius of approximately $50 \mathrm{~m}$ during foraging in the study period (Kazahari, personal observation). Thus, 50 quadrants of $100 \times 100 \mathrm{~m}$ were randomly located across the approximate range area (Figure 1a, b). The number of trees with $\mathrm{DBH}_{-} 5 \mathrm{~cm}$ was counted in each quadrant for each food item. The total number of trees in 50 quadrants was summed for each food item as an index of abundance (abundance of food trees). Additionally, the $m_{*} / m$ relationship (Iwao, 1968) was calculated for each food item as the spatial cohesiveness of food trees in the habitat.

\subsubsection{Relative energy content among available food items}

Data on the energy content per food unit for the main food items in the present study were taken from Tsuji et al. (2008), who presented the nutritional traits of various food items consumed by macaques at the study site (Table 2). The relative energy content of each food item in each season was estimated by dividing the energy content of each food item by the mean energy content of the main foods during each period.

\subsection{Data analysis}

\subsubsection{Patterns of relationships between feeding-group size and feeding rate}

The behavioural data collected when focal females were feeding in the food patches of subject food items were used for analysis. In food patches, focal females were feeding on the 12 main food items for $85 \%$ (range 70.3-94.0\%) of the total observation time during the first 4 min of sessions. The numbers of food units were counted on average $87 \%$ of the total feeding time (range 65.1-95.6\%).

Relationships between feeding-group size and feeding rate were examined using a generalized linear model (GLM) based on the maximum likelihood estimates method. Contest competition may decrease the feeding rate of lower-ranking females (Janson \& van Schaik, 1988). Patch size and within-patch food density also may affect feeding rate (e.g., Whitten, 1988). Thus, dominance rank of focal females, patch size, and index of within-patch food unit density were assigned as explanatory variables as well as the 
feeding-group size for each session (Table 3). Focal individual was not set as a random effect in the models, as dominance rank closely corresponded to individual females. To analyze feeding rate, we used the total number of food units consumed and the total feeding time in each session. The total number of food units consumed and the total feeding time in each session were assigned as the response variable and offset, respectively. These two variables corresponded to feeding rate. The response variable was assumed to follow a Poisson distribution with log link function. Akaike's information criterion (AIC) was evaluated for the full-model with the four explanatory variables and for sub-models with all possible combinations of the explanatory variables (total 14 sub-models) (Burnham \& Anderson, 2002). The minimum AIC model with $>2$ AIC differences from an alternative model is considered the best-fit model. According to the principal of parsimony, when the AIC difference was $<2$, a model with fewer parameters was selected (Burnham \& Anderson, 2002).When over-dispersion or under-dispersion appeared, the coefficients and standard errors were estimated again using a GLM with a quasi-Poisson error distribution. When feeding-group size was selected in the best-fit model, the relationship between feeding-group size and feeding rate was assumed to be positive or negative, based on the sign of the coefficient. Otherwise, the relationship was considered to be neutral.

For herbal patch food items (XI and XII), focal females sometimes fed on other food items in the patches. The sessions during which females fed for more than $30 \%$ of the time on other food items were excluded from the data analysis because these data were not assumed to represent data from the subject food items.

Table 3. Information about model structure in GLM analysis.

\begin{tabular}{|c|c|c|c|c|}
\hline Response variables & Explanatory variables & Offset & Error distribution & Link function \\
\hline \multicolumn{5}{|c|}{ (1) Patterns of relationship between feeding-group size and feeding rate } \\
\hline \multirow{4}{*}{$\begin{array}{l}\text { Feeding rate for each food type } \\
\text { (number of eaten food units) }\end{array}$} & Feeding-group size & \multirow{4}{*}{ Feeding time } & \multirow{4}{*}{ Poisson ${ }^{\star 3}$} & \multirow{4}{*}{$\log$} \\
\hline & Dominance rank & & & \\
\hline & Patch size & & & \\
\hline & Index of within-patch food unit density & & & \\
\hline \multicolumn{5}{|c|}{ (2) Characteristics of food items affecting the relationship between feeding-group size and feeding rate } \\
\hline \multirow{6}{*}{$\begin{array}{l}\text { Relationship of feeding group size and feeding rate } \\
\text { ("positive relationship" }=1 \\
\text { "neutral or negative relationships" }=0 \text { ) }\end{array}$} & Mean patch size (PS) & \multirow{6}{*}{-} & \multirow{6}{*}{ Binomial $^{\star 3}$} & \multirow{6}{*}{ Logit } \\
\hline & Cluster size of food units (CS) & & & \\
\hline & Within-patch food unit density (FD) & & & \\
\hline & Relative energy content (EC) & & & \\
\hline & Abundance of food tree $(\mathrm{AT})^{\star 2}$ & & & \\
\hline & Cohesiveness of food tree $(\mathrm{CT})^{* 2}$ & & & \\
\hline
\end{tabular}

\footnotetext{
${ }^{{ }^{*} 1}$ Model selections were conducted across 12 food items and across 10 food items excluding food items of herbal patch (i.e., food items XI and XII).

${ }^{\star 2}$ These factors were assigned as explanatiry variables in the full-model for analysis across 10 food items.

${ }^{\star 3}$ The coefficients and SE were estimated again using GLM with quasi error distribution (quasi-Poisson or quasi-binomial) when over-dispersion or under-dispersion appeared.
} 
2.5.2. Characteristics of food items affecting the relationship between feeding-group size and feeding rate The effects of characteristics of food items including (1) patch size, (2) cluster size of food units, (3) within-patch food unit density, (4) abundance and (5) cohesiveness of within-habitat food trees, and (6) relative energy content among available food items on the relationships between feeding-group size and feeding rate were examined. The effects of characteristics of food items on the probability of positive relationships were estimated using GLM. Four characteristics, i.e., mean food patch size (PS), cluster size of food units (CS), within-patch food unit density (FD), and relative energy content among available food items (EC), were assigned as explanatory variables for the 12 main food items (Table 3). Additionally, all six characteristics were assigned as explanatory variables for the 10 main food items $(I-X)$ excluding the two herbal patch food items (XI and XII). Positive and other (i.e., negative and neutral) relationships corresponded to one-zero data. Binomial distributions with logit link function were assumed for the response variables. The AIC was evaluated for the full-model and sub-models with all possible combinations of the explanatory variables (total 14 sub-models for the 10 food items and 62 sub-models for the 12 food items) (Burnham \& Anderson, 2002).We selected the best-fit models based on AIC values in similar method of examination (1). Coefficients and standard errors were estimated again using GLM with quasi-binomial distribution when over-dispersion or under-dispersion appeared.

\section{Results}

\subsection{Patterns of relationships between feeding-group size and feeding rate}

The AIC values for the full model and all possible sub-models for each food item are shown in Table 4. The coefficients and standard errors of the factors in the best-fit models are shown in Table 5. All coefficients and standard errors were estimated by GLM with quasi-Poisson distribution, because over-dispersions were observed.

The explanatory variables included in the best-fit models differed among food items (Table 4). Feeding-group size was selected with a positive coefficient for five of the 12 main food items (I, II, III, V and $\mathrm{VI}$ ) and with a negative coefficient for three items (IX, X and XII); none was selected for four items (IV, VII, VIII and XI) (Table 5). Thus, various relationships between feeding-group size and feeding rate were observed among food items: positive relationships, I, II, III, V and VI; neutral relationships, IV, VII, VIII and $\mathrm{XI}$; and negative relationships, IX, X and XII.

Dominance rank was selected with negative coefficients in the best-fit models for four food items (II, IV, $X$ and $\mathrm{XI}$ ). The mean frequency of aggressive interactions among females was 0.12 times $/ \mathrm{h}$ for the 12 food items, which was lower than that previously observed at the study site (0.42-0.75 times/h; Saito, 1996). Despite the rarity of aggressive interactions, lower-ranking females showed decreased feeding rates for these food items. Finally, patch size and index of within-patch food unit density were selected for six and eight food items in the best-fit models, respectively. These variables had both positive and negative influences on feeding rate (Table 5). 


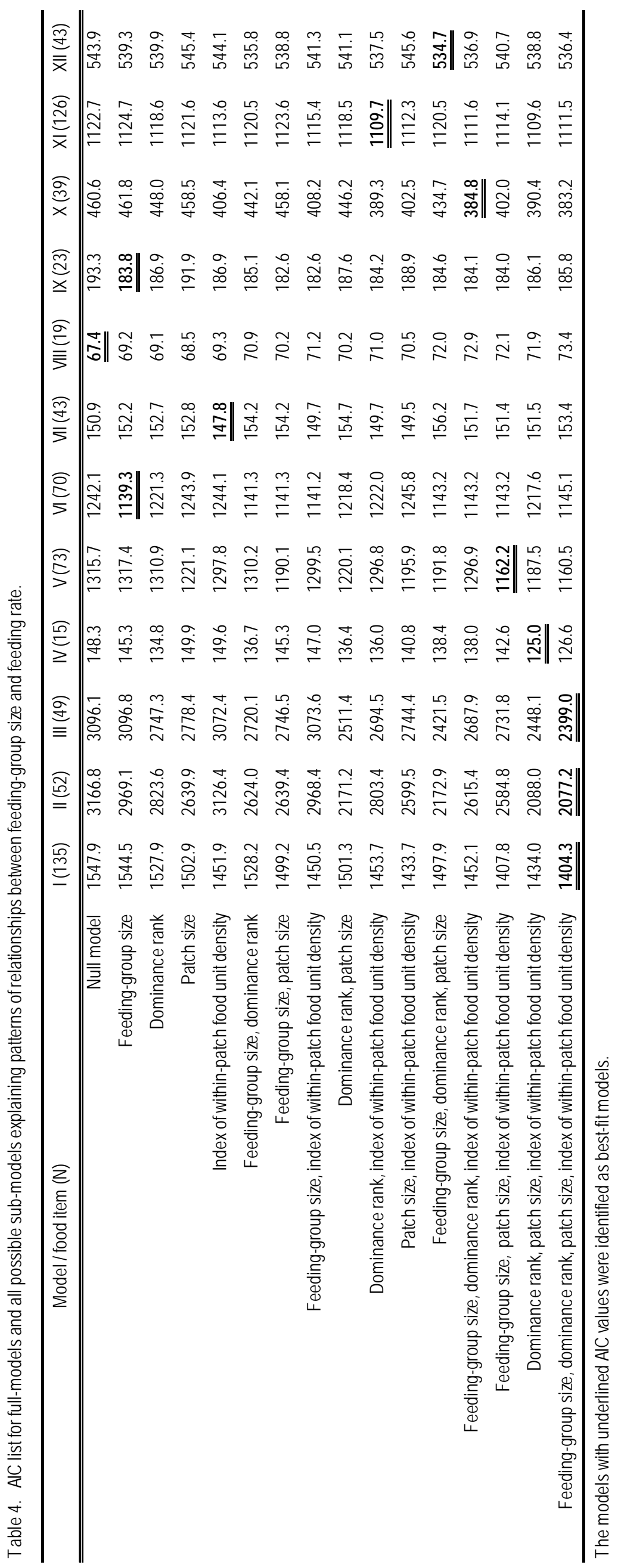


Table 5. Parameter estimates for best-fit models explaining relationships between feeding-group size and the other factors, and feeding rate.

\begin{tabular}{|c|c|c|c|c|c|}
\hline \multirow[b]{2}{*}{ Food items } & \multicolumn{5}{|l|}{ Coefficient (SE) } \\
\hline & Intercept & Feeding-group size & Dominance rank & Patch size & $\begin{array}{l}\text { Index of within-patch } \\
\text { food unit density }\end{array}$ \\
\hline $\bar{I}$ & "-0.411 (0.052) & $0.015(0.005)$ & 0.005 (0.005) & 0.000 '(0.000) & $\begin{array}{l} \\
-0.105(0.022)\end{array}$ \\
\hline$\|$ & $0.456(0.330)$ & $0.011(0.018)$ & $-0.062^{\top}(0.016)$ & $0.002(0.001)$ & $-0.163(0.095)$ \\
\hline III & $1.240 "(0.248)$ & $0.035 "(0.032)$ & 0.026 (0.001) & $-0.004(0.001)$ & 0.046 (0.062) \\
\hline IV & $2.364 "(1.150)$ & & -0.191 (0.068) & 0.006 (0.002) & -2.443 (1.015) \\
\hline V & $-0.669(0.081)$ & $0.0255^{\prime}(0.013)$ & & $-0.003(0.001)$ & $-0.041^{\prime}(0.024)$ \\
\hline $\mathrm{V}$ & $-1.034(0.099)$ & $0.055(0.017)$ & & & \\
\hline $\mathrm{VII}$ & $-3.383(0.127)$ & & & & -0.196 '(0.057) \\
\hline VIII & $-3.623(0.084)$ & & & & \\
\hline IX & $-2.025^{\prime}(0.214)$ & $-0.118(0.076)$ & & & \\
\hline$x$ & 0.068 (0.160) & $-0.022(0.011)$ & $-0.022(0.011)$ & & $0.325^{\prime}(0.049)$ \\
\hline$X I$ & $-1.783(0.088)$ & & -0.008 (0.007) & & $0.0499^{\prime}(0.031)$ \\
\hline XII & -1.199 (0.161) & $-0.012^{\prime}(0.016)$ & $0.044^{\prime \prime}(0.048)$ & $0.000 " 0.0000$ & \\
\hline
\end{tabular}

3.2. Characteristics of food items affecting the relationship between feeding-group size and feeding rate

The effects of the following food item characteristics on the relationships between feeding-group size and feeding rate were examined: (1) mean food patch size (PS); (2) cluster size of food units (CS); (3) within-patch food unit density (FD); (4) abundance (AT) and (5) cohesiveness of within-habitat food trees (CT); and (6) relative energy content among available food items (EC). AIC values for the full model and all possible sub-models are listed in Table 6 . The coefficients and standard errors of the factors involved in the best-fit models are shown in Table 7. All coefficients and standard errors were estimated by GLM with quasi-binomial distribution because overdispersions were observed.

AIC values were not obtained for several sub-models because the GLM algorithms did not converge. This tendency was found in models including more explanatory variables. The sample size was not sufficient for modeling with 4-6 explanatory variables. Even so, within-patch food unit density was consistently selected in the best-fit models across the 12 main food items and the 10 main food items excluding herbal items (Table 6). Consistent positive coefficients of within-patch food unit density indicated that higher food unit density induced positive relationships between feeding-group size and feeding rate (Table 7). In the analysis using the 10 food items, the coefficient of mean patch size was negative, that is, large patch size led to neutral or negative relationships. Thus, relationships between feeding-group size and feeding rate were affected by specific characteristics of food items, especially within-patch food unit density. 
Table 6. AlC list for full-models and all possible sub-models explaining characteristics of food items associating with relationship between feeding-group size and feeding rate.

\begin{tabular}{|c|c|c|c|c|}
\hline Across 12 food items & Across 10 food items & & & \\
\hline Model : AlC & Model : AIC & Model : AlC & Model : AIC & Model : AIC \\
\hline Null model : 18.3 & Null model : 15.9 & FD, EC: na & $\mathrm{CS}, \mathrm{FD}, \mathrm{EC}: \mathrm{na}$ & PS, FD, EC, CT : \\
\hline PS : 17.9 & PS : 17.9 & FD, AT : na & CS, FD, AT : na & PS, FD, EC, AT : 10 \\
\hline CS : 16.4 & CS : 12.4 & FD, CT : 11.1 & CS, FD, CT : 13.1 & PS, FD, AT, CT : 10 \\
\hline FD : 13.8 & FD : $\underline{\underline{9.7}}$ & EC, AT : 12.7 & CS, EC, AT : 13.9 & $\mathrm{PS}, \mathrm{EC}, \mathrm{AT}, \mathrm{CT}: \mathrm{na}$ \\
\hline EC : 19.0 & EC : 16.5 & EC, CT : 16.3 & CS, EC, CT : 16.3 & CS, EC, AT, CT : \\
\hline PS, CS : 14.4 & 13.7 & AT, CT : 15.0 & CS, AT, CT : na & $\mathrm{CS}, \mathrm{FD}, \mathrm{EC}, \mathrm{CT}:$ \\
\hline PS, FD : 10.4 & 14.4 & PS, CS, FD : 12.4 & $\mathrm{FD}, \mathrm{EC}, \mathrm{AT}: 8$ & $\mathrm{CS}, \mathrm{FD}, \mathrm{EC}, \mathrm{AT}: 10$ \\
\hline PS, EC : 18.6 & PS, CS : & PS, CS, EC : 16.4 & $\mathrm{FD}, \mathrm{EC}, \mathrm{CT}: 8$ & CS, FD, AT, CT : \\
\hline CS, FD : 15.3 & PS, FD : & PS, CS, AT : 15.2 & FD, AT, CT : na & $\mathrm{FD}, \mathrm{EC}, \mathrm{AT}, \mathrm{CT}: 10$ \\
\hline CS, EC : 18.2 & PS, EC : & PS, CS, CT : 16.4 & EC, AT, CT : na & PS, FD, EC, AT, CT : 12 \\
\hline FD, EC : 15.5 & PS, AT : & PS, FD, EC : na & PS, CS, EC, CT : 18.1 & PS, CS, EC, AT, CT : na \\
\hline PS, CS, FD : 152.2 & PS, CT : & PS, FD, AT : na & PS, EC, CS, AT : 10 & PS, CS, FD, EC, CT : \\
\hline PS, CS, EC : 16.4 & CS, FD : 11.5 & PS, FD, CT : na & PS, CS, AT, CT : na & PS, CS, FD, EC, AT : 12 \\
\hline PS, FD, EC : na & CS, EC : 14.4 & PS, EC, AT : na & PS, CS, FD, EC : na & PS, CS, FD, AT, CT : \\
\hline CS, FD, EC : 17.0 & CS, AT : 13.2 & PS, EC, CT : 16.7 & PS, CS, FD, CT : na & $\mathrm{CS}, \mathrm{FD}, \mathrm{EC}, \mathrm{AT}, \mathrm{CT}$ : \\
\hline PS, CS, FD, EC : na & CS, CT : 14.4 & PS, AT, CT : 16.7 & PS, CS, FD, AT : na & $\mathrm{PS}, \mathrm{CS}, \mathrm{FD}, \mathrm{EC}, \mathrm{AT}, \mathrm{CT}$ : \\
\hline
\end{tabular}

PS: Mean patch size; CS: Cluster size; FD: Within-patch food unit density, EC: Relative energy content, AT: Abundance of food trees, CT: Cohesiveness of food tree na: AlC values were not obtained because algorisms did not converge in the GLMs.

The models with underlined AIC values were decided as best-fit models.

Table 7. Parameter estimates for best-fit models explaining characteristics of food item associating with relationships between feeding-group size and feeding rate.

\begin{tabular}{|c|c|c|c|c|}
\hline \multirow[b]{2}{*}{ Explanatory variables } & \multicolumn{2}{|c|}{ Across 12 food items } & \multicolumn{2}{|c|}{ Across 10 food items } \\
\hline & Coefficient & SE & Coefficient & SE \\
\hline Intercept & -7.303 & 4.849 & -4.730 & 2.630 \\
\hline Mean patch size (PS) & -0.014 & 0.011 & & \\
\hline Cluster size of food unit (CS) & \multicolumn{2}{|c|}{ - } & \multicolumn{2}{|c|}{-} \\
\hline Within-patch food unit density (FD) & 0.062 & 0.038 & 0.030 & 0.016 \\
\hline Relative energy content (EC) & \multicolumn{2}{|c|}{-} & \multicolumn{2}{|c|}{-} \\
\hline Abundance of food trees (AT) & \multicolumn{2}{|c|}{ na } & \multicolumn{2}{|c|}{-} \\
\hline Cohesiveness of food trees (CT) & \multicolumn{2}{|c|}{ na } & \multicolumn{2}{|c|}{ - } \\
\hline
\end{tabular}

$-:$ variables not included in the best-fit models

na: variables not analyzed.

\section{Discussion}

We hypothesised that some characteristics of food items affect the intensity of feeding competition and modify the balance between the positive and negative impacts of other individuals on feeding rate, 
ultimately determining the relationships between feeding-group size and feeding rate. As a result, different patterns of relationships (i.e., positive, neutral, or negative relationships) are realized for different food items. As we expected, this study demonstrated that even the same individual showed different relationships between feeding-group size and feeding rate according to food items (Tables 4 and 5). Additionally, dominance rank negatively affected feeding rate for several food items (Tables 4 and 5), although agonistic interactions rarely occurred. This is likely because subordinates could not use beneficial sites realizing a higher feeding rate due to occupancy by dominants or to avoid interference from dominant individuals (Janson, 1985). Contest feeding competition was assumed to be provoked at least for these four food items (II, IV, X and XI).

Second, based on our hypothesis, positive relationships were predicted when macaques were feeding on food items with characteristics associated with reduced feeding competition. In our results, food items exhibiting higher within-patch food unit density and/or smaller patch size were associated with positive relationships (Table 7). Relaxed feeding competition (i.e., negative impact of feeding group size on feeding rate) resulting from higher within-patch food unit density (Peres, 1996) would lead to such positive relationships. Food items of smaller patches were also associated with positive relationships across 10 food items, although larger patch size should reduce feeding competition (Mitchell et al., 1991). The ecological and behavioural reasons for this were not revealed by the present study. Positive relationships with food items in smaller patches might be exhibited under the influence of neutral or negative relationships in two herbal patches (i.e., food items XI and XII) with substantially larger patch sizes than others.

Our results conclusively indicate that the relationships between feeding-group size and feeding rate can change with specific characteristics of food items that would regulate the intensity of feeding competition. The reason for the inconsistent relationships between feeding-group size and feeding rate previously found in primates (Chapman, 1988; Barton, 1993; Snaith \& Chapman, 2005; Furuichi \& Hashimoto, 2007; Kazahari \& Agetsuma, 2008) may be differences in the characteristics of the food items depended on by study subjects. In fact, positive relationships have been observed under food-rich conditions without patch depletion or scramble feeding competition (Kazahari \& Agetsuma, 2008). Conversely, a negative relationship was observed when food patches were depleted (Snaith \& Chapman, 2005). The present paper shows a mechanism explaining how the relationships between feeding-group size and feeding rate are determined in group-living primates. This mechanism could also apply to other group-living animals that depend on food resources characterized by patch distribution. Focusing on the costs and benefits to individuals in foraging success will help us to understand how group living has evolved.

\section{Acknowledgements}

Dr. K. Izawa of the Association for the Research on Monkeys in Miyagi Prefecture (ARMMP) offered valuable help and information 
on the study site. The staff of the Kinkazan Koganeyama Shrine and members of ARMMP provided hospitality and assistance during fieldwork. Mr. H. Kazahari assisted with the survey of food characteristics. We greatly appreciated fruitful discussions with the staff and researchers of the Field Science Center for the Northern Biosphere, Hokkaido University. This study was partially funded by the Cooperative Research Fund of the Primate Research Institute, Kyoto University to N. K. This research was also supported by the Environment Research and Technology Development Fund (D-1007) of the Ministry of the Environment, Japan.

\section{References}

Agetsuma, N. (1995a). Foraging strategies of Yakushima macaques (Macaca fuscata yakui). —Int. J. Primatol. 16: 595-609.

Agetsuma, N. (1995b). Dietary selection by Yakushima macaques (Macaca-fuscata yakuI): the influence of food availability and temperature. - Int. J. Primatol. 16: 611-627.

Agetsuma, N. (1998). Simulation of patch use by monkeys using operant conditioning. - J. Ethol. 16: 49-55.

Alexander, R.D. (1974). The evolution of social behavior. — Annu. Rev. Ecol. System 5: 325-383.

Altmann, J. (1974). Observational study of behaviour: sampling method. — Behaviour 49: 227-267.

Barrett, G.M., Shimizu, K., Bardi, M., Asaba, S. \& Mori, A. (2002). Endocrine correlates of rank, reproduction, and female-directed aggression in male japanese macaques (Macaca fuscata). - Horm. Behav. 42: 85-96.

Barton, R.A. (1993). Sociospatial mechanisms of feeding competition in female olive baboons, Papio anubis.- Anim. Behav. 46: 791-802.

Berger, J. (1978). Group size, foraging, and antipredator ploys: an analysis of bighorn sheep decisions. — Behav. Ecol. Sociobiol. 4: 91-99.

Burnham, K.P. \& Anderson, D.R. (2002).Model selection and multi-model inference: a practical information-theoretic approach.Springer, New York, NY.

Caraco, T. (1979). Time budgeting and group size: a theory.—Ecology 60: 611-617.

Chapman, C. (1988). Patch use and patch depletion by the spider and howling monkeys of Santa Rosa National Park, Costa Rica. - Behaviour 105: 99-116.

Charnov, E.L. (1976). Optimal foraging, the marginal value theorem. — Theor. Popul. Biol. 9: 129-136.

Clark, C.W. \& Mangel, M. (1986). The evolutionary advantages of group foraging.-Theor. Popul. Biol. 30: 45-75.

Cowie, R.J. (1977). Optimal foraging in great tits (Parus major). - Nature 268: 137-139.

Furuichi, T. \& Hashimoto, C. (2007). Pattern of use of food patches by chimpanzees in Kalinzu Forest: analyses of ecological and sociological factors. — Primate Res. 23: S-13 (in Japanese).

Hill, D.A. \& Agetsuma, N. (1995). Supra-annual variation in the influence of Myrica rubra fruit on the behavior of a troop of Japanese macaques in Yakushima. — Am. J. Primatol. 35: 241-250.

Ito, T. (1974). The Japanese deer in Kinkazan Island. — Mammal. Sci. 14: 29-36 (in Japanese).

Iwao, S. (1968). A new regression method for analyzing the aggression pattern of animal populations. -Res. Popul. Ecol. X: 1-20. Iwasa, Y., Higashi, M. \& Yamamura, N. (1981). Prey distribution as a factor determining the choice of optimal foraging strategy.

-Am. Nat. 117: 710-723.

Izar, P., Ferreira, R.G. \& Sato, T. (2006). Describing the organization of dominance relationships by dominance-directed tree 
method._Am. J. Primatol. 68: 189-207.

Izawa, K. (1983). The ecological study of wild Japanese monkeys living in Kinkazan Island, Miyagi Prefecture. — Bull. Miyagi Univ. Educ. 18: 24-45 (in Japanese).

Izawa, K. (2005). Results of the census of the Kinkazan population of Japanese macaques in 2004.- Jpn. Monkeys Miyagi Prefect. 20: 21-26 (in Japanese).

Janson, C.H. (1985). Aggressive competition and individual food consumption in wild brown capuchin monkeys (Cebus apella). Behav. Ecol. Sociobiol. 18: 125-138.

Janson, C.H. (1988). Food competition in brown capuchin monkeys (Cebus apella): quantitative effects of group size and tree productivity. -Behaviour 105: 53-76.

Janson, C.H. \& van Schaik, C.P. (1988). Recognizing the many faces of primate food competition: methods.- Behaviour 105: 165-186.

Kacelnik, A. (1984). Central place foraging in starlings (Sturnus vulgaris). 1. Patch residence time. —J. Anim. Ecol. 53: 283-299.

Kazahari, N. \& Agetsuma, N. (2008). Social factors enhancing foraging success of a wild group of Japanese macaques (Macaca fuscata) in a patchy food environment. - Behaviour 145: 843-860.

Kazahari, N. \& Agetsuma, N. (2010). Mechanisms determining relationships between feeding group size and foraging success in food patch use by Japanese macaques (Macaca fuscata). -Behaviour 147: 1481-1500.

Krause, J. \& Ruxton, G.D. (2002). Living in groups.- Oxford University Press, Oxford.

Krebs, J.R., Ryan, J.C. \& Charnov, E.L. (1974). Hunting by expectation or optimal foraging? A study of patch use by chickadees. - Anim. Behav. 22: 953-964.

Livoreil, B. \& Giraldeau, L.A. (1997). Patch departure decisions by spice finches foraging singly or in groups.-Anim. Behav. 54: 967-977.

McFarland, M.S. (1988). Food competition and foraging party size in the black spider monkey (Ateles paniscus chamek).Behaviour 105: 117-134.

Maruhashi, T., Saito, C. \& Agetsuma, N. (1998). Home range structure and inter-group competition for land of Japanese macaques in evergreen and deciduous forests. — Primates 39: 291-301.

Mitchell, C.L., Boinski, S. \& van Schaik, C.P. (1991). Competitive regimes and female bonding in two species of squirrel monkeys (Saimiri oerstedi and S. sciureus). — Behav. Ecol. Sociobiol. 28: 55-60.

Nakagawa, N. (1989). Bioenergetics of Japanese monkeys (Macaca fuscata) on Kinkazan Island during winter. —Primates 30 : 441-460.

Nakagawa, N. (1990). Decision on time allocation to different food patches by Japanese monkeys (Macaca fuscata). — Primates 31: 459-468.

Peres, C.A. (1996). Food patch structure and plant resource partitioning in interspecific associations of Amazonian tamarins. — Int. J. Primatol. 17: 695-723.

Saito, C. (1996). Dominance and feeding success in female Japanese macaques, Macaca fuscata: effects of patch size and inter-patch distance. - Anim. Behav. 51: 967-980.

Saito, C., Sato, S., Suzuki, S., Sugiura, H., Agetsuma, N., Takahata, Y., Sasaki, C., Takahashi, H., Tanaka, T. \& Yamagiwa, J. 
(1998). Aggressive intergroup encounters in two populations of Japanese macaques (Macaca fuscata). - Primates 39: 303-312.

van Schaik, C.P. (1983). Why are diurnal primates living in groups? — Behaviour 98: 120- 144.

Schmid-Hempel, P., Kacelnik, A. \& Houston, A.I. (1985). Honeybees maximize efficiency by not filling their crop.-Behav. Ecol. Sociobiol. 17: 61-66.

Snaith, T.V.\& Chapman, C.A. (2005). Towards an ecological solution to the folivore paradox: patch depletion as an indicator of within-group scramble competition in red colobus monkeys (Piliocolobus tephrosceles).-Behav. Ecol. Sociobiol. 59: 185-190. Stephens, D.W. \& Krebs, J.R. (1986). Foraging theory.-Princeton University Press, Princeton, NJ.

Sullivan, K.A. (1984). The advantages of social foraging in downy woodpeckers. - Anim. Behav. 32: 16-22.

Tanaka, I. (1992). Three phases of lactation in free-ranging Japanese macaques. — Anim. Behav. 44: 129-139.

Terborgh, J.W. (1983). Five New World primate species: a study in comparative ecology. — Princeton University Press, Princeton, NJ.

Thouless, C.R. (1990). Feeding competition between grazing red deer hinds.-Anim. Behav. 40: 105-111.

Takatsuki, S. (2009). Effects of sika deer on vegetation in Japan: a review. — Biol. Conserv. 142: 1922-1929.

Tsuji, Y. (2011). Sleeping-site preferences of wild Japanese macaques (Macaca fuscata): the importance of nonpredatory factors. — J. Mamm. 92: 1261-1269.

Tsuji, Y., Fujita, S., Sugiura, H., Saito, C. \& Takatsuki, S. (2006). Long-term variation in fruiting and the food habits of wild Japanese macaques on Kinkazan Island, northern Japan.—Am. J. Primatol. 68: 1068-1080.

Tsuji, Y., Kazahari, N., Kitahara, M. \& Takatsuki, S. (2008). A more detailed seasonal division of energy balance and the protein balance of Japanese macaques (Macaca fuscata) on Kinkazan Island, northern Japan. —Primates 49: 157-160.

Tsuji, Y. \& Takatsuki, S. (2012). Interannual variation in nut abundance is related to agonistic interactions of foraging female Japanese macaques (Macaca fuscata). — Int. J. Primatol. 33: 489-512.

Whitten, P.L. (1988). Effects of patch quality and feeding subgroup size on feeding success in vervet monkeys (Cercopithecus aethiops). -Behaviour 105: 35-52.

Wrangham, R.W. (1980). An ecological model of female-bonded primate groups. — Behaviour 75: 262-300.

Yoshii, Y. \& Yoshioka, K. (1949). Plant communities of Kinkazan Island. — Ecol. Rev. Sendai 12: 84-105 (in Japanese).

Yoshioka, K. (1972). Conservation of ecosystem on Kinkazan Island I. — Japan J. Ecol. 22(2): 6-7 (in Japanese). 